\title{
2 Case Reports Intoxication from Smoking "Spice”
}

\author{
N A Aliyev ${ }^{1 *}$ and Z N Aliyev ${ }^{2}$ \\ ${ }^{1}$ Department of psychiatry and addiction, Baku, Azerbaijan \\ ${ }^{2}$ Department of psychiatry, Baku, Azerbaijan
}

*Corresponding author: N A Aliyev, Azerbaijan State Advanced Training Institute for Doctors named by A Aliyev Department of psychiatry and addiction, Baku, Azerbaijan

\section{Introduction}

"Spice" refers to herbal compounds sold as frankincense and a legal alternative to marijuana. Product descriptions suggest that such compounds produce an effect similar to that of tetrahydrocannabinol, the active ingredient in marijuana. Studies have shown that many spice products are sprayed with synthetic cannabinoids, the actual substances responsible for intoxication [1] It is known that Synthetic cannabinoids are part of a group of drugs called new psychoactive substances. New psychoactive are unregulated mind-altering substances that have become newly available on the market and are intended to produce the same effects as illegal drugs. Some of these substances may have been around for years but have reentered the market in altered chemical forms, or due to renewed popularity [2].

\section{Case 1}

The patient was examined at the mental health center the Ministry of Health of the Republic of Azerbaijan. Patient 1 was a 21-year-old male who vomited and reported having seizures approximately 1 hour after smoking an herbal product called Spicy XXX. Upon arrival, he was mildly tachycardic and tachyptic In the mental status of patients, almost all the symptoms of mental disorders are found: disturbance of appearance and behavior, hostile, agitated, depressed, compulsions, delusions, hallucinations, depersonalization, derealization, Orientation (time, place, person, situation), attention (concentration) and memory, absence and generalized convulsions, qualitative and quantitative disorders of consciousness, nausea and vomiting and other symptoms. He considers his father to be his son.

\section{Case 2}

The patient was examined at the Republican Psychiatric Hospital, the Ministry of Health of the Republic of Azerbaijan. Patient 2 was a 23-year-old male who suppressed with confusion and repeated vomiting about 1 hour after smoking Spicy XXX. He was sleepy and focused only on man. When he woke up, he was excited and fighting. In this patient also meet all the symptoms of mental disorders are found: disturbance of appearance and behavior, hostile, agitated, depressed, compulsions, delusions, hallucinations, depersonalization, derealization, Orientation (time, place, person, situation), attention (concentration) and memory, absence and generalized convulsions, qualitative and quantitative disorders of consciousness, nausea and vomiting and other symptoms. he considers his father to be his son.

Common clinical features in our patients included agitation, vomiting, drowsiness, tachycardia, mydriasis, and a rather long duration of symptoms. We in the world psychiatry did not find such a symptom when the patient believes that he is the father of his son, that is, he considers his father to be his son. At the same time, the identity of the mother remains untouched. Although we could not objectively confirm the presence of synthetic cannabinoids in these patients with currently available urine screening screens, each of which was presented after the spice product was discovered.

\section{References}

1. Deluca P, Schifano F, Davey Z (2009) Spice Report by the Psychonaut Web Mapping Research Project. London, England: Institute of Psychiatry, King's College London 2009.

2. National Institute on Drug Abuse (NIDA) National Institutes of Health, US. 
(C) This work is licensed under Creative Commons Attribution 4.0 License

To Submit Your Article Click Here: Submit Article

DOI: $10.32474 / 0 J N B D .2018 .02 .000131$

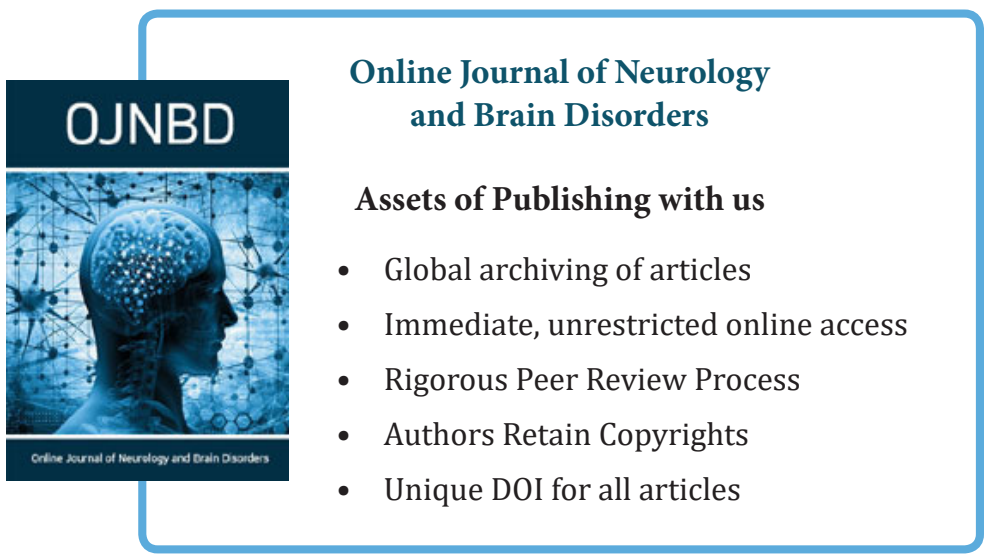

